\title{
Development of cost-effective protocol for preparation of dehydrated paneer (Indian cottage cheese) using freeze drying
}

\author{
Sharma, S. ${ }^{a^{*}}$; Nema, P. H. ${ }^{a}$; Emanuel, N. ${ }^{\text {a }}$;ingha, S. ${ }^{b}$ \\ ${ }^{a}$ National Institute of Food Technology Entrepreneurship and Management, Haryana, 131028, India \\ ${ }^{\mathrm{b}}$ Centre for Rural Technology, Indian Institute of Technology, Guwahati, Assam 781039, India
}

*E-mail of the corresponding author: $\underline{\text { sadhana.foodtech@gmail.com }}$

\begin{abstract}
Nowadays, there is high consumer demand in the market for simple to prepare, convenient, healthy and natural foods. Paneer or Indian cottage cheese is an acid and heat coagulated milk product which serves as a rich source of animal proteins for the vegetarians. Due to high moisture content (58-60\%), it is highly perishable in nature. Drying of paneer would undoubtedly extend the shelf life of paneer and also help in value-addition of paneer. Dehydrated paneer would find numerous ways to be use. Drying of paneer by conventional methods poses threats including case-hardening and non-uniform incomplete drying, poor rehydration characteristics, longer drying time, yellow discoloration and oiling off during drying. Freeze drying remains the best in retaining the quality of dried food products. Though it is highly expensive due to high processing and operation costs. The present study focuses on developing cost-effective protocol for freeze-drying of paneer. Efforts have been made by use of pre-treatments prior subjecting to freeze drying. The dehydrated product would be shelf-stable and can be rehydrated to its original state having flavor and texture comparable to the fresh form. Moreover, the final product after rehydration would be more fresh and softer than its frozen counterparts. The developed product would be easily kept well for few years at room temperature without any addition of preservatives.
\end{abstract}

Keywords: Paneer; freeze-drying; color; rehydration ratio; pre-treatment 


\section{Introduction}

Paneer is an important indigenous product which is obtained by heat treating the milk followed by acid coagulation using suitable acid viz. citric acid, lactic acid, tartaric acid, alum, sour whey. Traditionally, India has been a paneer consuming nation with about $5 \%$ of milk produced being converted into paneer [1]. As per a conservative estimate, Indian paneer market is expected to grow at Compound annual growth rate of $18 \%$ till 2020. Paneer is quite popularly being used in a number of traditional Indian recipes. It is highly perishable with about $58 \%$ moisture content (wb). Various attempts have been made to improve the shelf life of paneer by employing different physical and chemical methods. These include low temperature treatment (refrigeration and freezing), chemical treatment, heat treatment, drying, hurdle technology and packaging. However drying remains the best preservation method in achieving a shelf stable product while retaining the quality attributes, it alters the physicochemical characteristics in the dried product. Vishweshwariah (1987) achieved a shelf-life of up to 2 months dehydrated paneer (5-9 \% moisture) dried using hot air drying at $75^{\circ} \mathrm{C}$ for $4 \mathrm{hrs}$. Rehydration characteristics of were poor and lacked cohesiveness due to irreversible denaturation of proteins and rehydrated paneer was tough and rubbery [2]. Srivastava et al. (2013) reported that time required for drying paneer is $33 \%$ higher in VD as compared to low pressure superheated steam drying (LPSSD). Moreover, the effective diffusivity decreased with increase in pressure during vacuum drying of paneer [3]. Singh et al. (2004) conducted hot and cold diffusion of paneer cubes with sodium chloride and potassium sorbate solution and subsequent microwave drying was done. Maximum rehydration ratio was achieved in cold (1.03) and hot (1.09) diffused microwave dried paneer cubes at $30^{\circ} \mathrm{C}$ for 10 minutes [4]. Undoubtedly, Freeze drying is a standard processing technique for drying of heat sensitive food materials. However, due to its high cost of operation the technology the cost of FD may be as much as $200-500 \%$ higher than that of hot air drying, which greatly reduced economic competitiveness of FD products. Hence to widen its application, various approaches have been studied to modify the freeze-drying process. Pre-treatment prior to drying is a good approach to improve the drying kinetics while retaining the product quality. Blanching is known to enhance mass transport in the tissue and affect the drying behavior. Similarly, osmotic pre-treatment with calcium chloride affects the rigidity of the cell membrane and thus assist in removal of water from the tissues during drying. In an effort to reduce drying time, and indirectly the energy consumption, the present research aims to study the effect of pre-treatments viz blanching and calcium choride treatment on the drying characteristics and product qualities of paneer dried with freeze drying. Dried paneer offers numerous culinary applications. It can be used in curry preparation similar to paneer-in-curry, a delicacy in Indian cuisine. It may be added to granola/ trail mix, soup mix, yielding a high energy snack. If grounded to a powder, it may be use as a cheesy spice mix, or used as 
popcorn seasoning. Dried paneer powder may be added to pizza dough or added to a white sauce to turn it into a paneer sauce.

\section{Materials and Methods}

\subsection{Material}

Paneer was kept at $4{ }^{\circ} \mathrm{C}$ in a refrigerator until use. The initial moisture content of paneer was about $55 \%(w b)$. It was diced in to a cube of two size $1 \times 1 \times 1 \mathrm{~cm} 3$ with stainless steel knife.

\subsection{Pre-treatments}

Paneer cubes were pretreated with two different ways (i) blanching and (ii) dipping in salt solution. Hot Water blanching was carried out by immersing paneer cubes into $100^{\circ} \mathrm{C}$ for 1 min distilled water in a stainless steel pan heated by an induction cooking plate. The weight ratio of paneer cubes and distilled water was 1:2. After the pretreatment, the samples were cooled using a fan until there was no visible water on the surface of the material. The blanching pretreatment was carried out in triplicate. Salt treatment was done by dipping paneer cubes in solution containing $0.5 \%$ calcium chloride for $10 \mathrm{~min}$. Paneer cubes and salt solution was in the ratio of 1:10. After pretreatment cubes were then removed, and drained using stainless steel mesh. Before drying, samples were blotted to remove the surface moisture and put in the drying chamber.

\subsection{Drying Equipment and Procedure}

Freeze drying (FD) was performed in a laboratory-scale FDL-10N-50-8M freeze-dryer (MRC, Beijing, China) for $12 \mathrm{hrs}$ and $18 \mathrm{hrs}$ to evaluate the difference in moisture content reduction and quality achieved at the two time intervals. The paneer cubes $(200 \mathrm{~g})$ were frozen at $-20^{\circ} \mathrm{C}$ in a freezing chamber and freeze-dried to a moisture content of 5-6\% (w.b.) at an absolute pressure of 0.100 mbar with a chamber temperature of $20^{\circ} \mathrm{C}$ and a condenser temperature $-50^{\circ} \mathrm{C}$. The dehydrated paneer samples were packaged into polyethylene bags with silica gel.

\subsection{Moisture Content}

Moisture content was determined by the hot air oven method. At regular time intervals during the drying process, samples were taken out and dried for $8 \mathrm{~h}$ at $105^{\circ} \mathrm{C}$ until constant weight. The initial moisture content of the paneer was found to be $54.52 \%$ (w.b.). The tests were performed in triplicate.

\subsection{Measuring of Energy Consumption}

Industrial freeze drying processes is complicated and quite expensive. For making it feasible for a sumptuous food such as paneer, a lower cost approach to this process needs to 
be researched. However, the energy consumption of a drying process is measured by energy cost checker, but for the present study emphasis is given to predict which pre-treatment is the best in maximally reducing the moisture content in given time duration, $12 \mathrm{hrs}$ and 18 hrs. This will assist to indirectly reduce the overall energy consumption of the drying.

\subsection{Color}

The color is one of the most important appearance attribute of food materials since it influences consumer acceptability [5]. The color measurements can be used in an indirect way to estimate color change of foods since it is simpler and faster than chemical analysis. Hunter color parameters (L, a, b) have previously proved valuable in describing visual color deterioration. The color of raw and dried samples Colour measurement was done by using Colorimeter (Model: Chroma Meter CR-400, Konica Minolta). The location of any color in the CIELAB color space is determined by its color coordinates, CIEL* $\left(L^{*}=0\right.$ (black) and $\mathrm{L}^{*}=100$ (white)), $\mathrm{CIEa}^{*}\left(-\mathrm{a}^{*}=\right.$ greenness and $+\mathrm{a}^{*}=$ redness), and $\mathrm{CIEb}^{*}\left(-\mathrm{b}^{*}=\right.$ blueness and $+\mathrm{b}^{*}=$ yellowness). The paneer cubes were scanned at three different locations to determine the average $L^{*}, a^{*}$ and $b^{*}$ values as the average of the five measurements. The paneer cubes were cut into small portion with knife and put into adapter for color measuring. The total color differences (TCD) were estimated from the coordinates of the color by applying the following equation (1):

$$
\left.T C D=\sqrt{(L}_{0}^{*}-L\right)^{2}+\left(a_{0}^{*}-a\right)^{2}+\left(b_{0}^{*}-b\right)^{2}
$$

where, $\mathrm{L}_{0} *$ is the degree of lightness of control sample, $\mathrm{a}_{0} *$ is the degree of redness and greenness at control sample and $b_{0} *$ is the degree of yellowness and blueness at control sample.

\subsection{Rehydration Process}

Dried food products are usually rehydrated before consumption. Rehydration can be in general defined as a complex process involving different physical processes such as capillary flow, convection or diffusion [6]. Rehydration capacity indicates degree of damage (cell or structure disruptions) to foodstuff caused during drying. It involves imbibition of water, swelling and finally leaching out of soluble solids from dried food stuffs [7]. Rehydration capacity is studied by reconstituting the dried product in distilled water and amount of equilibrium moisture absorbed within a stipulate time is determined.. Treatments such as drying and rehydration produce changes in the structure and composition of product tissues [8]. The dried paneer cubes were soaked in controlled temperature of $100^{\circ} \mathrm{C}$ distilled water and were analysed for weight gain after every $1 \mathrm{~min}$ by first removing surplus water from the surface using blotting paper. The weight used in each experiment was $1 \pm 0.1 \mathrm{~g}$ of dehydrated paneer samples. The weighing was performed on a digital balance. A dried paneer cube was added to $150 \mathrm{~mL}$ of distilled water. The 
sample weighing was performed in triplicate. The rehydration ratio (RR) was evaluated from equation (2) below:

$$
R R=\frac{M_{r}}{M_{d}}
$$

where $M_{r}$ is the weight of paneer cubes after rehydration (g) and $M_{d}$ is the weight of paneer cubes after drying $(\mathrm{g})$

\subsection{Statistical Analysis}

Data analyses were determined and analyses of variance (ANOVA) were conducted by ANOVA procedure. Mean values were considered significantly different when $\mathrm{P}<0.05$.

\section{Results and Discussion}

In order to assess the advantage of the pre-treatment prior to freeze drying, the reduction in moisture content, color, and rehydration between the pre-treated dried products were compared. The freeze dried (FD) sample with no pre-treatment was used as a control.

\subsection{Amount of moisture removed}

There has been more reduction in the moisture content when the sample was pre-treated. Blanching for 2 minutes significantly increased the amount of water removed up to $57 \%$ and $22.6 \%$ as compared to the control sample for both $12 \mathrm{hrs}$ and $18 \mathrm{hrs}$ drying duration respectively(Table 1). This was because blanching causes disruption of cell membranes and a concomitant faster and more complete drying [7]. This implies that with use of blanching, the time of drying can be reduced, and therefore the overall energy consumption.

Table 1. Effect of Pre-Treatment and drying time on Moisture Content of Dehydrated Paneer

\begin{tabular}{|l|l|l|l|}
\hline Pre-treatment & $\begin{array}{l}\text { Drying } \\
\text { time } \\
(\mathrm{hrs})\end{array}$ & $\begin{array}{l}\text { Final moisture } \\
\text { content (\%, w.b.) }\end{array}$ & $\begin{array}{l}\text { \% Reduction in } \\
\text { final moisture } \\
\text { content in control } \\
\text { sample }\end{array}$ \\
\hline $\begin{array}{l}\text { Control sample } \\
\text { (No pre- } \\
\text { treatment) }\end{array}$ & 12 & 15.207 & - \\
\hline \multirow{2}{*}{ Blanching (1 min) } & 12 & 7.522 & - \\
\cline { 2 - 4 } & 18 & $\mathbf{6 . 4 4 5}$ & 25.4 \\
\hline \multirow{2}{*}{ Blanching (2 min) } & 12 & 6.522 & 14.3 \\
\cline { 2 - 4 } & 18 & 5.825 & 57 \\
\hline $\mathrm{CaCl}_{2}$ & 12 & 8.155 & $\mathbf{2 2 . 6}$ \\
\cline { 2 - 4 } & 18 & 6.275 & $\mathbf{1 6 . 4}$ \\
\hline
\end{tabular}

Initial moisture content $=54.52 \% \mathrm{wb}$ 


\subsection{Color of paneer cubes associated with different pre-treatments}

The drying causes many changes in color of paneer cubes irrespective of any pre-treatments done. TCD for all drying treatments with respect to the control (FD) is reported in Table 2. It was observed that the color of pre-treated paneer cubes was significantly darker ( $\mathrm{L}$ value) in comparison with fresh paneer cubes. Out of the pre-treated samples, the lowest value for color change was observed in blanching ( $2 \mathrm{mins})$ for $18 \mathrm{hrs}$ dried paneer cubes.

Table 2. Colour Difference of dried paneer cubes after pre-treatments

\begin{tabular}{|c|c|c|c|c|c|}
\hline \multirow[t]{2}{*}{ Pre-treatment } & \multirow{2}{*}{$\begin{array}{l}\text { Drying } \\
\text { time (hrs) }\end{array}$} & \multicolumn{4}{|c|}{ Color parameters } \\
\hline & & $L$ & $a$ & b & TCD \\
\hline \multirow{2}{*}{$\begin{array}{l}\text { Control sample } \\
\text { (No pre-treatment) }\end{array}$} & 12 & 56.53 & 2.31 & 17.28 & 40.62 \\
\hline & 18 & 61.28 & 3.61 & 18.64 & 36.78 \\
\hline \multirow[t]{2}{*}{ Blanching (1 min) } & 12 & 60.24 & 2.9 & 16.84 & 39.56 \\
\hline & 18 & 61.2 & 3.08 & 17.18 & 36.24 \\
\hline \multirow[t]{2}{*}{ Blanching (2 min) } & 12 & 62.53 & 3.04 & 16.75 & 35.67 \\
\hline & 18 & 63.86 & 3.15 & 17.19 & 33.80 \\
\hline \multirow[t]{2}{*}{$\mathrm{CaCl2}$} & 12 & 59.08 & 3.28 & $\mathbf{1 7 . 8 5}$ & 38.49 \\
\hline & 18 & 60.23 & 3.2 & 15.52 & 36.61 \\
\hline Fresh paneer & - & 80.20 & 1.65 & 11.01 & 16.29 \\
\hline
\end{tabular}

\subsection{Effect of different pre-treatments on RR and moisture content of dried paneer cubes}

The values of the RR for the different drying methods dried paneer sample are detailed in Table 3. In all the rehydration trials, there was an initial reduction in the weight of the sample followed by a constant increase. This loss in weight may be due to the fat oozing out in the water during rehydration. This fat loss process might opens pathway and creates space, surface micro-holes and capillaries for more water imbibitions resulting in an increase in the weight. This consolidated, rigid structure leads to the absence of pathways for water access. The RR was slightly higher, affected by $\mathrm{CaCl}_{2}$ treatment, showing a $3.6 \%$ and $9 \%$ increase in $12 \mathrm{hrs}$ and $18 \mathrm{hrs}$ dried sample respectively as compared to the control. 
Table 3. Rehydration ratio of Freeze dried paneer for different pre-treatments

\begin{tabular}{|l|l|l|l|}
\hline Pre-treatment & $\begin{array}{l}\text { Drying time } \\
(\mathrm{hrs})\end{array}$ & $\begin{array}{l}\text { Maximum Rehydration Ratio } \\
(\mathrm{RR})\end{array}$ & $\begin{array}{l}\text { \% Increase } \\
\text { in RR }\end{array}$ \\
\hline $\begin{array}{l}\text { Control sample } \\
\text { (No pre-treatment) }\end{array}$ & 12 & 1.12 (after 8 mins) & - \\
\cline { 2 - 4 } & 18 & 1.11 (after 9.5 mins) & - \\
\hline Blanching (1 min) & 12 & 1.06 (after 6.5 mins) & - \\
\cline { 2 - 5 } & 18 & 1.1 (after 10 mins) & - \\
\hline Blanching (2 min) & 12 & 1.1 (after 10 mins) & - \\
\cline { 2 - 5 } & 18 & 1.06 (after 3.5 mins) & - \\
\hline CaCl $_{2}$ & 12 & 1.16 (after 5.5 mins) & 3.6 \\
\cline { 2 - 5 } & 18 & 1.21 (after 14.5 mins) & 9 \\
\hline
\end{tabular}

*(-) implies no increase in the RR value, either it remains same or decreases.

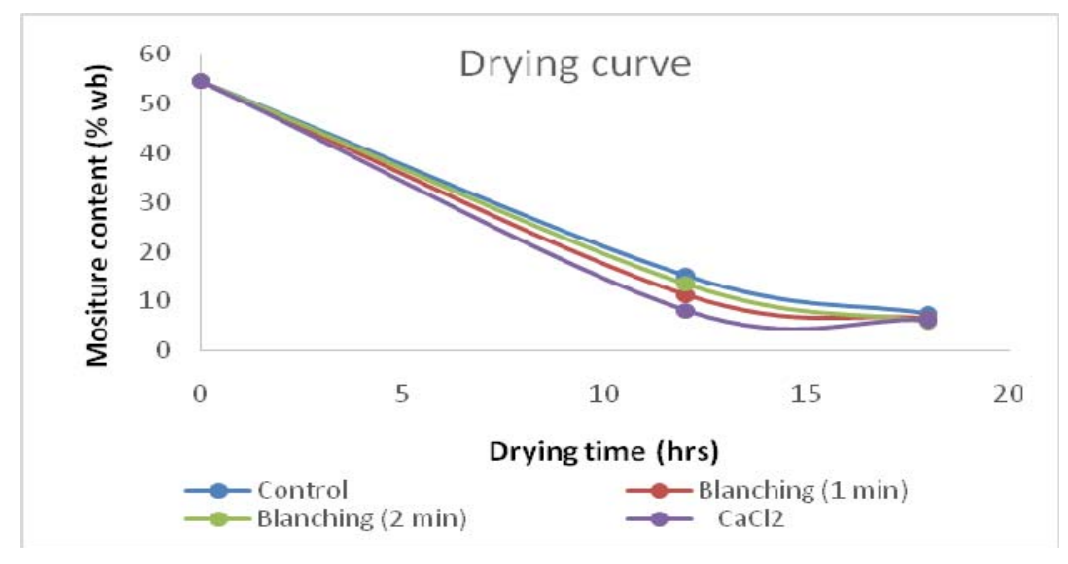

Fig. 1 Moisture content after 12 hrs and 18 hrs freeze drying

From the figure 1, it can be clearly observed that like $\mathrm{CaCl}_{2}$ can reduce the drying time by $30 \%$ as compared to the control sample. This was followed by blanched $(1 \mathrm{~min})$ and then by blanched (2min).

\section{Conclusions}

By comparing the two pre-treatments i.e. blanching for $1 \mathrm{~min} .2 \mathrm{~min}$ and $\mathrm{CaCl}_{2}$ dipping for $10 \mathrm{~min}$, it can be concluded that blanching promises to increase more amount of water removal from the paneer cubes. Also, the color loss was least in the blanched dried sample. But for a good rehydration ratio, $\mathrm{CaCl}_{2}$ proves to be a good pre-treatment as compared to blanching. Moreover, it is more probable that by combining air drying and freeze drying better quality can be achieved in reduced time and energy consumption. 


\section{Acknowledgement}

The author expresses her sincere thanks to Dr. Mariyam Sarwat (Assistant Professor), Department of Pharmacy, Amity University, U.P) for providing necessary facilities for conducting certain experiments for this work.

\section{References}

[1] Chandan RC. Manufacture of paneer. In: Gupta S, Gupta S, editors. Dairy India 2007. 6. New Delhi: Dairy India Yearbook, A Dairy India publication; 2007a. pp. $411-412$.

[2] Vishweshwariah, L. (1987). Studies on dehydration and deep freezing of paneer. J. of Food Sci. \& Tech. 24(2): 95-96.

[3] Srivastava, S. and Kumbhar, B. K. (2013). A Comparative study of low pressure superheated steam (LPSS) and vacuum drying (VD) of paneer. Agricultural Engineering Today, 37(2): 7-13.

[4] Singh, S., Rai, T. (2004). Process optimization for diffusion process and microwave drying of paneer. J Food Sci Technol 41(5):487-491.

[5] Maskan, M. 2001. Kinetics of color change of kiwifruits during hot air and microwave drying. J. Food Eng. 48, 169-175.

[6] Vreeker, R., Li, L. and Fang, Y. (2008). Drying and Rehydration of Calcium Alginate Gels. Food Biophysics, 3:361-369.

[7] Jamradloedluk, J., Nathakaranakule, A., Soponronnarit, S., and Prachayawarakorn, S. (2007). Influences of drying medium and temperature on drying kinetics and quality attributes of durian chip. Journal of Food Engineering, 78: 198-205.

[8] Cox, S., Gupta, S. and Abu-Ghannam, N. 2012. Effect of different rehydration temperatures on the moisture, content of phenolic compounds, antioxidant capacity and textural properties of edible Irish brown seaweed. LWT - Food Sci. Technol. 47, 300-307.

[9] Acevedo, N.C., Briones, V., Buera, P. and Aguilera, J.M. 2008. Microstructure affects the rate of chemical, physical and color changes during storage of dried apple discs. J. Food Eng. 85, 222-231. 